\title{
Temporary Visual Deprivation Causes Decorrelation of Spatiotemporal Population Responses in Adult Mouse Auditory Cortex
}

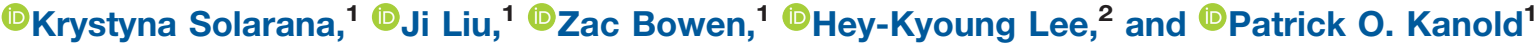

https://doi.org/10.1523/ENEURO.0269-19.2019

${ }^{1}$ Department of Biology, University of Maryland, College Park, MD 20742 and ${ }^{2}$ Department of Neuroscience, Mind/ Brain Institute, Johns Hopkins University, Baltimore, MD 21218

\begin{abstract}
Although within-modality sensory plasticity is limited to early developmental periods, cross-modal plasticity can occur even in adults. In vivo electrophysiological studies have shown that transient visual deprivation (dark exposure, DE) in adult mice improves the frequency selectivity and discrimination of neurons in thalamorecipient layer 4 (L4) of primary auditory cortex (A1). Since sound information is processed hierarchically in A1 by populations of neurons, we investigated whether DE alters network activity in A1 L4 and layer 2/3 (L2/3). We examined neuronal populations in both $\mathrm{L} 4$ and $\mathrm{L} 2 / 3$ using in vivo two-photon calcium $\left(\mathrm{Ca}^{2+}\right)$ imaging of transgenic mice expressing GCaMP6s. We find that one week of DE in adult mice increased the sound evoked responses and frequency selectivity of both $L 4$ and $L 2 / 3$ neurons. Moreover, after DE the frequency representation changed with L4 and L2/3 showing a reduced representation of cells with best frequencies (BFs) between 8 and $16 \mathrm{kHz}$ and an increased representation of cells with BFs above $32 \mathrm{kHz}$. Cells in L4 and L2/3 showed decreased pairwise signal correlations (SCs) consistent with sharper tuning curves. The decreases in SCs were larger in L4 than in L2/3. The decreased pairwise correlations indicate a sparsification of $A 1$ responses to tonal stimuli. Thus, cross-modal experience in adults can both alter the sound-evoked responses of A1 neurons and change activity correlations within A1 potentially enhancing the encoding of auditory stimuli.
\end{abstract}

Key words: auditory cortex; cross-modal; dark exposure; plasticity; visual deprivation

\section{Significance Statement}

Our results show that the brief period of visual deprivation in mice can alter the tone evoked responses of neurons as well as the frequency representation in multiple layers of the primary auditory cortex (A1). Thus, the tuning of auditory cortex neurons can be altered even after the critical period. Moreover, our results show that pairwise correlations are decreased indicating a sparsification of the evoked responses in the auditory cortex. These results add to the mounting evidence that cross-modal sensory experience has the power to alter network circuitry and population dynamics even into adulthood.

\section{Introduction}

A hallmark of sensory cortices is their ability to rewire in response to environmental input especially during critical periods in development (Wiesel and Hubel, 1963; Hubel and Wiesel, 1970; de Villers-Sidani et al., 2007; Sanes and

Received July 11, 2019; accepted November 5, 2019; First published November 19, 2019.

The authors declare no competing financial interests.
Bao, 2009; Barkat et al., 2011). Loss of a sensory modality can engage plasticity in the remaining senses in a compensatory manner. Humans experiencing vision loss from birth exhibit cross-modal perceptual enhancement of hearing, including improved sound localization abilities 
Table 1. Animals, fields, and cell numbers imaged

\begin{tabular}{llccccc}
\hline Group & Layer & Animals & Fields & Mean depth & Total cells & Responding cells \\
Control & L2/3 & 8 & 15 & $189 \pm 4 \mu \mathrm{m}$ & 1573 & 989 \\
DE & L4 & 9 & 14 & $370 \pm 11 \mu \mathrm{m}$ & 1202 & 846 \\
& L2/3 & 6 & 19 & $191 \pm 4 \mu \mathrm{m}$ & 1919 & 682 \\
& L4 & 6 & 14 & $354 \pm 41 \mu \mathrm{m}$ & 1099
\end{tabular}

Responding cells denote neurons from the total cell population that showed a significant tone-evoked response to at least one frequency (ANOVA across 10 repetitions, $p<0.001)$.

(Lessard et al., 1998; Voss et al., 2004), frequency discrimination performance (Gougoux et al., 2004), and auditory spatial tuning (Röder et al., 1999). Cats binocularly deprived from birth and juvenile ferrets with binocular eye suture both show a significant compensatory enhancement in auditory spatial acuity, particularly in peripheral sound localization (Rauschecker and Kniepert, 1994; King and Parsons, 1999). Remarkably, the capacity for crossmodal induced plasticity is not fully extinguished in adulthood, but the circuit basis for these perceptual enhancements is unclear. Following prolonged visual deprivation, adult ferrets also show improved peripheral auditory spatial acuity (King and Parsons, 1999). Compensatory plasticity in the auditory domain is not only limited to early onset or prolonged vision loss, but can be observed when vision loss occurs later in life and over a shorter period. In humans, late-onset blindness can enhance auditory localization (Voss et al., 2004), and even brief periods of visual deprivation can transiently improve auditory perception by enhancing sound source segregation (Pagé et al., 2016).

On a cellular level, brief periods of visual deprivation in rodents (dark exposure, DE) after the critical period in A1 increase frequency selectivity, lower thresholds, and increase neuronal firing rates of single neurons in L4 of A1 (Petrus et al., 2014). These changes on the single cell level likely result from altered neuronal circuits. Indeed, DE induces potentiation of thalamic input to $L 4$, strengthening of ascending intracortical connections from L4 to L2/3 neurons (Goel et al., 2006; Petrus et al., 2014, 2015), refinement of both excitatory and inhibitory intralaminar connections within L2/3 as well as interlaminar ascending connections from $L 4$ to $L 2 / 3$ (Meng et al., 2015) and feedback connections from L2/3 to L4 (Meng et al., 2017a). These circuit changes are consistent with the

This work was supported by the Department of Health and Human Services (HHS) National Institutes of Health $(\mathrm{NIH})$ National Eye Institute Grant R01EY022720 (to H.-K.L. and P.O.K.) and HHS NIH National Institute on Deafness and Other Communication Disorders Grant T32DC000046 (to K.S.).

Acknowledgements: We thank Dr. Dan Nagode for help with cell-attached recordings; Dr. Paul Watkins, Dr. Daniel Winkowski, and Dr. Xiangying Meng for help with analysis code; and Philip Gross and John Krstacic for help with cell identification.

Correspondence should be addressed to Patrick O. Kanold at pkanold@umd.edu.

https://doi.org/10.1523/ENEURO.0269-19.2019

Copyright (C) 2019 Solarana et al.

This is an open-access article distributed under the terms of the Creative Commons Attribution 4.0 International license, which permits unrestricted use, distribution and reproduction in any medium provided that the original work is properly attributed. observed changes in L4 responses in vivo. However, sensory stimuli are not entirely encoded by single neurons but by populations of neurons and the network activity patterns as well as activity correlations between neurons can contribute to information encoding (Averbeck et al., 2006). Thus, changes in synaptic function must be coordinated across neurons to improve network function.

Since the representation of sound frequency preference differs between $L 4$ and $L 2 / 3$ of $A 1$ with $L 2 / 3$ showing more heterogeneous organization than L4 (Bandyopadhyay et al., 2010; Rothschild et al., 2010; Winkowski and Kanold, 2013; Kanold et al., 2014; Maor et al., 2016), we examined whether DE in adulthood can restructure the mesoscale organization and connectivity of A1 using in vivo two-photon calcium $\left(\mathrm{Ca}^{2+}\right)$ imaging. We measured the sound evoked activity from L2/3 and L4 A1 neurons in adult mice following one week of DE which was initiated after the critical period for spectral tuning (>P21). We observed that single cells in both $L 4$ and $L 2 / 3$ show increased frequency selectivity. However, we found that after DE fewer neurons preferred tones in the midfrequency region. Moreover, we find that after DE activity correlations between local neurons in both $L 4$ and L2/3 were reduced indicating a decorrelation of the population activity in A1. These experiments reveal that besides altering the tuning of single neurons, DE can alter network activity and population dynamics in adulthood, long after the canonical critical period for auditory and visual plasticity has ended (Goel et al., 2006; Barkat et al., 2011; Petrus et al., 2014, 2015; Meng et al., 2015). Thus, crossmodal plasticity might be more powerful than withinmodality plasticity in rewiring cortical circuits. Moreover, given that visual deprivation is easily established, crossmodal plasticity could potentially be used for targeted modifications of $\mathrm{A} 1$.

\section{Materials and Methods}

To study the cross-modal plasticity of A1 we used in vivo two-photon $\mathrm{Ca}^{2+}$ imaging in 15 in-house bred male and female Thy1-GCaMP6s (GP4.3) transgenic mice (JAX strain 024275; Dana et al., 2014; normal-reared, NR, $n=$ 9 , P38 \pm 9.7 ; DE, $n=6, \mathrm{P} 40 \pm 9$ ) before the onset of high-frequency hearing loss in C57BI/6 mice (Zheng et al., 1999). Mice were split into two groups, and either placed in a dark room for $7 \mathrm{~d}$ (DE) or left in a normal 12/12 $\mathrm{h}$ light/dark cycle (NR; Table 1). All animal procedures were approved by the University of Maryland's Animal Care and Use Committee. 


\section{Cranial window procedure}

Mice were initially anesthetized with $4 \%$ isoflurane (Fluriso, VetOne) using a calibrated vaporizer (Matrix VIP 3000 ), which was reduced to $2-2.5 \%$ for the craniotomy procedure to maintain stable anesthesia. Body temperature was maintained near $37^{\circ} \mathrm{C}$ with a heating block. Tissue overlying the left auditory cortex was exposed and the skull was affixed to a custom titanium headplate using cyanoacrylate glue (Loctite Prism 454). A small circular craniotomy (3-4 $\mathrm{mm}$ in diameter) was performed to expose the surface of the auditory cortex, as determined by skull and vascular landmarks (Stiebler et al., 1997; Dorr et al., 2007). A circular glass coverslip (5 mm, \#0 thickness, Warner Instruments) was fixed to the surface of the craniotomy with $1.5-2 \%$ warm agarose (Sigma-Aldrich) to dampen pulsations, and was secured with glue on the outer edges to the headplate. For the DE group, mice were maintained in darkness during transfer to the surgery room and anesthesia induction and visualized under infrared illumination. Before beginning the cranial window procedure, mice from both control and DE groups had their eyes sealed shut and covered with black tape, as in our prior experiments (Petrus et al., 2014).

\section{Two-photon $\mathrm{Ca}^{2+}$ imaging}

Imaging was largely performed as described previously (Winkowski and Kanold, 2013). Body temperature was maintained at $37^{\circ} \mathrm{C}$ using a homeothermic blanket system (Harvard Apparatus) and a flexible probe to monitor internal temperature. Isoflurane levels were maintained at $1-1.5 \%$ for the duration of the imaging session. To prevent cortical cooling and avoid network cortical dysregulation, a constant perfusion of warmed saline $\left(35-37^{\circ} \mathrm{C}\right)$ was allowed to flow over the cover-slipped surface of the craniotomy (Kalmbach and Waters, 2012).

Imaging was performed using a two-photon microscope (Ultima, Prairie Technologies) and a MaiTai DeepSee laser (Spectra-Physics), equipped with a GaAsP photo detector module (Hamamatsu) and resonant scanners enabling high-resolution scanning at $30-60 \mathrm{~Hz}$ per frame. Excitation was set at $900 \mathrm{~nm}$ and focused at $180-200 \mu \mathrm{m}$ beneath the pia for supragranular L2/3 and $300-400 \mu \mathrm{m}$ for thalamorecipient L4 imaging. Regions within $\mathrm{A} 1$ were scanned at $30 \mathrm{~Hz}(\sim 300 \times 300 \mu \mathrm{m})$ through a 20×, 0.95 NA water-immersion objective (Olympus), with image resolution at $0.58 \mu \mathrm{m} / \mathrm{pixel}$. Since ACX organization is fairly stereotypical in inbred mice (Stiebler et al., 1997; Liu et al., 2019), we targeted midfrequency regions based on vascular landmarks.

\section{Auditory stimulation}

Sound stimuli were generated in MATLAB using custom software, presented, and attenuated using Tucker-Davis Technologies RX6, ED1 (Electrostatic Speaker Driver), and PA5 (Programmable Attenuator), and delivered with a free field TDT ES1 speaker placed close to the contralateral (right) ear. Sound intensity was calibrated with a microphone (Brüel \& Kjær 4944-A). Sounds were played at $60-\mathrm{dB}$ SPL $(\sim 30 \mathrm{~dB}$ above mouse hearing threshold for C57BL/6J mice (Zheng et al., 1999), the background strain for the Thy1-GCaMP6s strain used). Auditory stim- uli consist of 400-ms-long sinusoidal amplitude-modulated (SAM) tones $(5-\mathrm{Hz}$ modulation, cosine phase), ranging from 4 to $64 \mathrm{kHz}$ at quarter octave spacing (spanning four octaves). Each of these 17 stimuli was repeated 10 times with a 6- to 10-s interstimulus interval, for a total of 170 iterations. For each stimulus iteration, a sequence of 100 images were acquired for a duration of $3.3 \mathrm{~s}$, with sound onset at $1.5 \mathrm{~s}$ (or at about the 45th frame).

\section{Data analysis}

For image analysis, image sequences were first loaded into ImageJ $(\mathrm{NIH})$ to visually examine whether fluorescent responses were present and whether there were any artifacts from brain motion. Rigid motion correction was performed on image sequences using the ImageJ TurboReg plug-in. Raw fluorescence signals $(F)$ of auditory neurons were directly used to calculate frequency time course traces. Cells were manually selected as ring-like regions of interest (ROls) that cover soma but exclude cell nuclei, and pixel intensity within each ROI was averaged to generate fluorescence over time. Neuropil correction was performed by selecting a circular region with a radius of $20 \mu \mathrm{m}$ around the cell, excluding all pixels that are contained within other ROls. For each neuropil mask, the brightest $20 \%$ of pixels were also excluded as they might be neural processes from adjacent cells that are also tonally tuned, which otherwise will bias cell response to a smaller value or introduce irregularities in response patterns (Peron et al., 2015). The average fluorescence of this area (background fluorescence, $F_{B}$ ) was then subtracted from the cell's fluorescence at each time point. Changes in fluorescence $(\Delta F / F)$ were calculated as $\left[\left(F-r * F_{B}\right)-\left(F_{0}\right.\right.$ $\left.\left.-r * F_{B}\right)\right] /\left(F_{0}-r * F_{B}\right)$ (Kerlin et al., 2010; Chen et al., 2012), where $F_{0}$ is estimated by taking the 5 th percentile value of the entire subtracted fluorescence trace (for some cells 10th percentile value is chosen to avoid negative $F_{0}$ ), and $r$ is the contamination ratio 0.7 (Peron et al., 2015). To identify responsive cells, we compared the fluorescence in the stimulus period to the pre-stimulus period. A responsive cell was defined as a cell that showed an increased fluorescence during the stimulus period significantly above baseline $(p<0.001$, ANOVA) for at least one of the presented stimuli. Only significantly responding cells were analyzed further. Mean time course traces were generated by averaging fluorescence traces over ten repeats, and frequency-tuning curves were determined by taking the maximum $(\Delta F / F)$ from the mean time course trace across the frames following sound onset. Best frequency (BF) was then defined as the peak of the frequency-tuning curve (the tone which elicits the maximum $\Delta F / F$ at $60 \mathrm{~dB}$ ). Spontaneous activity is measured by variance during baseline frames preceding stimulus onset. To estimate baseline activity, the SD of the $\Delta \mathrm{F} / \mathrm{F}$ values of baseline (pre-stimulus) frames across all stimulus presentation trials was determined for each pixel, then averaged. This yielded a single value of baseline $\Delta \mathrm{F} / \mathrm{F}$ variability for each animal. The values of baseline variability were grouped either according to age or rearing condition and compared. Pairwise signal and noise correlation (NC) were calculated as previously described 
(Liu et al., 2019). We calculated pairwise correlations for all neurons in the imaged field. In brief, NCs were calculated by taking the individual response to each repeat of a sound stimulus, subtracting out the mean response to that particular stimulus, and measuring the covariance of the concatenated responses from every single trial of different stimuli. When trial number is small for each stimulus, signal correlations (SCs) can be strongly biased by NCs (Rothschild et al., 2010, 2013), and thus to overcome this bias, we calculate corrected SCs based on Rothschild et al. (2010):

$$
\operatorname{SC}_{\text {corrected }}(i, j) \triangleq \frac{\operatorname{cov}_{\text {corrected }}\left(r_{i}, r_{j}\right)}{\sqrt{\operatorname{cov}\left(r_{i}, r_{i}\right) \cdot \operatorname{cov}\left(r_{j}, r_{j}\right)}} .
$$

Unlike Rothschild et al. (2010), in the denominator, we used uncorrected expression for $\operatorname{cov}\left(r_{i}, r_{i}\right)$ because in practice, $\operatorname{cov}_{\text {corrected }}\left(r_{i}, r_{i}\right)$ can yield negative values for particular $r_{i}$.

\section{Cell-attached recordings of action potentials in vitro}

Cell-attached patch clamp recordings were performed in vitro in voltage clamp to simultaneously measure spiking activity and $\Delta F / F$. Thalamocortical slices containing primary auditory cortex (A1) were prepared as previously described (Zhao et al., 2009; Meng et al., 2015). The extracellular recording solution consisted of artificial CSF (ACSF) containing the following: $130 \mathrm{mM} \mathrm{NaCl}, 3 \mathrm{mM} \mathrm{KCl}$, $1.25 \mathrm{mM} \mathrm{KH}_{2} \mathrm{PO}_{4}, 20 \mathrm{mM} \mathrm{NaHCO}_{3}, 10 \mathrm{mM}$ glucose, 1.3 $\mathrm{mM} \mathrm{MgSO}{ }_{4}$, and $2.5 \mathrm{mM} \mathrm{CaCl}_{2}(\mathrm{pH} 7.35-7.4$, in $95 \%$ $\mathrm{O}_{2}-5 \% \mathrm{CO}_{2}$ ). Action potentials were recorded extracellularly in loose-seal cell-attached configuration (seal resistance typically 20-30 MOhm) in voltage clamp mode. Borosilicate glass patch pipettes were filled with normal ACSF diluted $10 \%$, and had a tip resistance of $\sim 3-5$ $\mathrm{MOhm}$ in the bath. Data were acquired with a Multiclamp 700B patch clamp amplifier (Molecular Devices), low-pass filtered at 3-6 kHz, and digitized at $10 \mathrm{kHz}$ using the MATLAB-based Ephus software (Suter et al., 2010). Action potentials were stimulated either by (1) a bipolar electrode placed in L1 or L2/3 to stimulate the apical dendrites of pyramidal cells (pulse duration 1-5 ms) or (2) gradually increasing the extracellular $\mathrm{K}^{+}$concentration (up to $\sim 8 \mathrm{mM}$ ) until spontaneous action potentials began to occur. Data were analyzed offline using MATLAB.

\section{Results}

We aimed to investigate whether a brief period of visual deprivation (DE) altered the single cell and population responses in L2/3 and L4 in A1 (Fig. 1A). To visualize the activity of $A 1$ neurons we used two-photon $\mathrm{Ca}^{2+}$ imaging in Thy1-GCaMP6s (GP4.3) mice (JAX strain 024275; Dana et al., 2014) that were randomly assigned to $\mathrm{DE}(n=6)$ or NR $(n=9$; Table 1) groups (NR P38 \pm 9.7 ; DE P40 \pm 9). $\mathrm{Ca}^{2+}$ imaging allowed us to measure responses from hundreds of neurons in each layer (Table 1). Since $\mathrm{Ca}^{2+}$ indirectly reports neuronal activity, we first tested whether DE altered the relation of spiking activity to cellular $\mathrm{Ca}^{2+}$ dynamics. Prior in vitro studies indicated that $\mathrm{DE}$ does not cause changes in intrinsic spiking properties of L4 and
L2/3 cells (Meng et al., 2015, 2017a). We performed cellattached patch clamp recordings in vitro (in voltage clamp) to simultaneously measure spiking activity and $\Delta F / F$. The recordings showed that $D E$ did not alter the amplitude of spike-induced fluorescence transients (Fig. $1 C)$. Together with the fact that DE did not cause changes in intrinsic spiking properties of L4 and L2/3 cells (Meng et al., 2015, 2017a), these data suggest that DE did not change the intrinsic properties and $\mathrm{Ca}^{2+}$ dynamics of $\mathrm{A} 1$ neurons.

\section{DE increases the amplitude of sound-evoked responses in L4 and frequency selectivity of single neurons in both L2/3 and L4}

To characterize the single-cell response properties of neurons in control and DE mice, we imaged $\sim 300 \times 300$ $\mu \mathrm{m}$ regions within $\mathrm{L} 2 / 3$ and $\mathrm{L} 4$ and presented pure tones (4-64 kHz, $60 \mathrm{~dB}$; Fig. 1D). We first identified cells that responded to these tonal stimuli. A cell was classified as responsive if it responded significantly to at least one of the presented stimuli. After DE, the fraction of tonally responsive cells in L4 did not change, however, in L2/3 fewer cells responded to these tonal stimuli (Fig. 1E) indicating a sparsification of cortical responses in supragranular layers.

Single unit microelectrode recordings have shown that L4 cells in DE animals have higher spontaneous and peak evoked firing rates (Petrus et al., 2014). We thus investigated whether these changes on the single cell level after DE were also present in L2/3. To evaluate the spontaneous activity of GCaMP6s-expressing neurons, we measured the fluorescence transients preceding the onset of the stimulus and during long-duration imaging without any stimulus presentation. We characterized the spontaneous activity as the SD of the fluorescence trace. The spontaneous activity increased in both L4 and L2/3 after DE (Fig. 1F). Thus, DE increased spontaneous activity in both $L 4$ and $L 2 / 3$ and this increase in spontaneous activity is unlikely to underlie the decreased responsiveness in L2/3.

The decrease in tonal responsiveness could be due to altered frequency tuning of A1 neurons. Prior microelectrode recordings have shown that $L 4$ cells in DE animals have increased frequency selectivity (Petrus et al., 2014) and since L2/3 receives input from L4 (Meng et al., 2015, 2017a) such changes could also be present in L2/3. We thus generated tuning curves for each responding cell based on the maximum evoked response during tone presentation (Fig. $2 A$ ). We first measured the amplitude of the evoked responses at the BF. The amplitude of the evoked responses after DE was increased in both layers, but the magnitude of change was larger in L4 (Fig. 2B). This is consistent with electrophysiological recordings and the strengthening of thalamocortical afferents to L4 (Petrus et al., 2014). We next evaluated the frequency selectivity of cells in DE and NR mice by calculating the bandwidth of the tuning curves. We measured the normalized bandwidth using a peak-related threshold $\left(\mathrm{BW}_{60 \%}\right)$ to characterize changes in tonal receptive fields. We find that the bandwidth was decreased in both $L 4$ and L2/3 
A

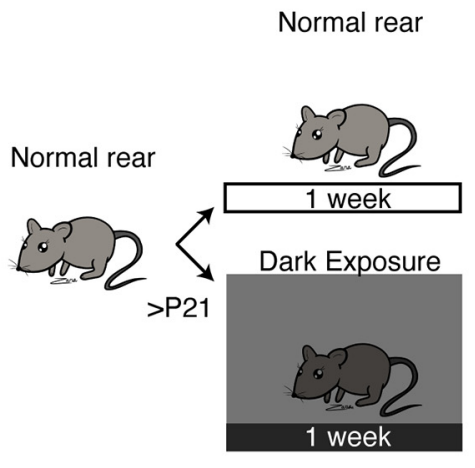

B

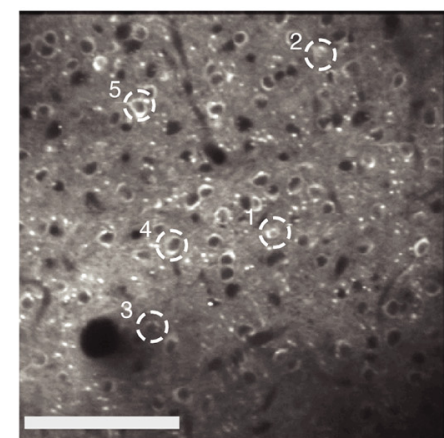

C

Spike $\Delta F / F$
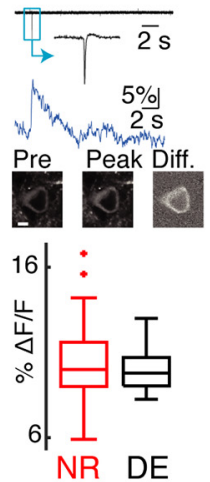

D
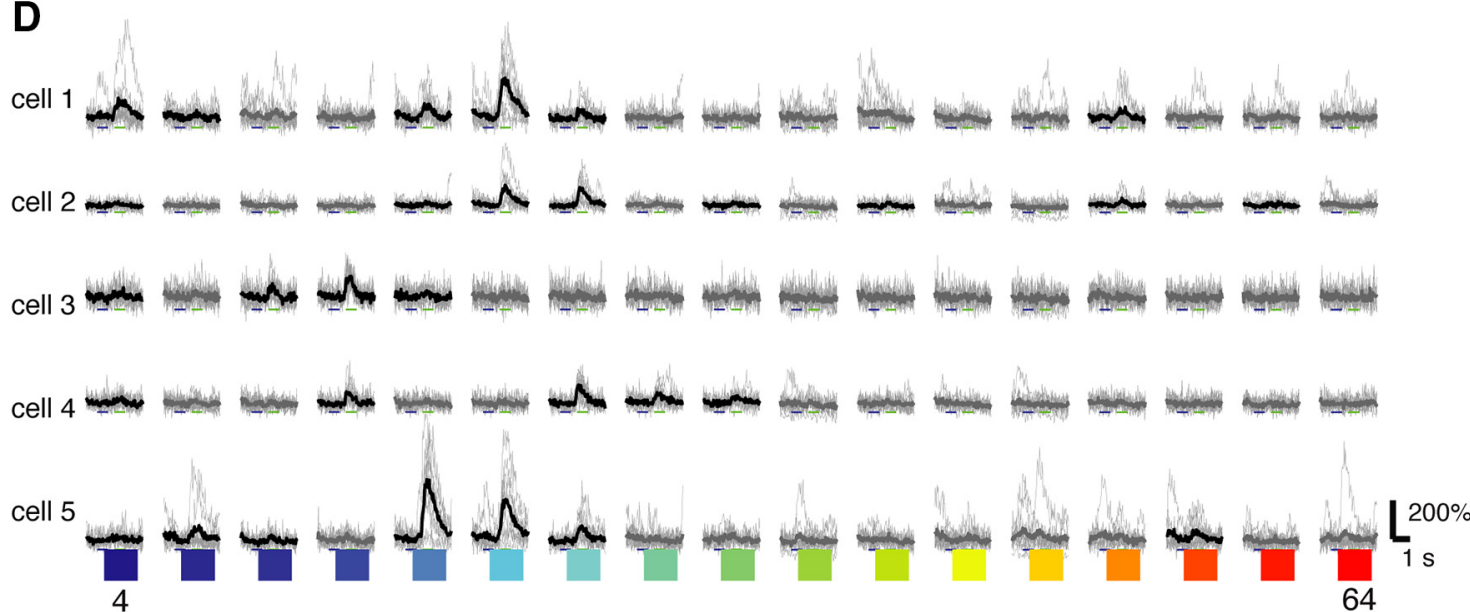

E

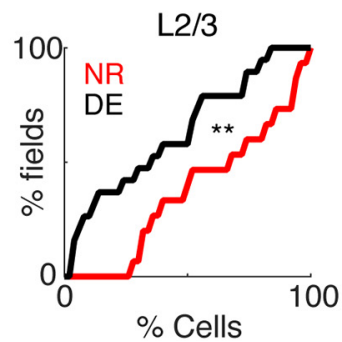

$\%$ Responding cells

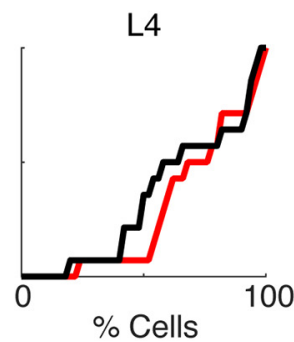

$\mathbf{F}$
64

Figure 1. Two-photon $\mathrm{Ca}^{2+}$ imaging of GCaMP6s neurons in A1. A, Experimental paradigm. Animals are raised in normal environments until at least P21. Animals then either stay in the normal lighted environment or are DE for $7 \mathrm{~d}$. Cartoon by Zara Kanold-Tso. B, Imaged field with GCaMP6-expressing neurons. Exemplar neurons indicated by white circles. Scale bar $=100$ $\mu \mathrm{m}$. C, Cell-attached patch recordings in vitro from GCaMP6S-expressing neurons. Top row shows current trace, with inset showing magnified action potential. Middle row shows the corresponding $\mathrm{Ca}^{2+}$ rise $(\Delta F / F)$ in response to one action potential. Bottom row shows the corresponding two-photon fluorescence images: first image is of cell preceding spike, middle image is of cell at peak of fluorescent response, and third image shows the difference (scale bar $=5 \mu \mathrm{m}$ ). Boxplots shows median and interquartile range of fluorescent-evoked responses to one spike in control and DE mice. DE does not alter the amplitude of spike-induced fluorescence transients (mean $\Delta \mathrm{F} / \mathrm{F} \pm \mathrm{SEM}$ per spike: $\mathrm{NR}=10.25 \pm 0.29 \%, n=62$ spikes; $\mathrm{DE}=9.97 \pm 0.20 \%$, $n=37$ spikes; two-sample Kolmogorov-Smirnov test, $p=0.16)$. $\boldsymbol{D}$, Sound evoked fluorescence traces in five exemplar cells (indicated in $\boldsymbol{B}$ ). Black lines indicate mean trace for responses that passed the significance criterion (ANOVA $p<0.001$ ), while thin gray traces show individual trials. Colors indicate tone frequency $4-64 \mathrm{kHz}$. $E$, Fraction of responsive cells decreases in $\mathrm{L} 2 / 3$ following $\mathrm{DE}$ (mean $\pm \mathrm{SD}, \mathrm{NR}=64.2 \pm 26.9 \%$, DE $=37.4 \pm 28.4 \%$, Wilcoxon rank-sum test, $p=0.0167$ ) with no change in $\mathrm{L} 4(\mathrm{NR}=72.1 \pm 22.0 \%, \mathrm{DE}=66.9 \pm 25.4 \%, p=0.35) . \boldsymbol{F}$, Spontaneous activity, as measured by SD of the baseline in $\Delta \mathrm{F} / \mathrm{F}$ traces, increased in $\mathrm{L} 4$ and $\mathrm{L} 2 / 3$ after $\mathrm{DE}(\mathrm{NR}$ median \pm iqr $\mathrm{L} 2 / 3=6.1 \pm 4.7, \mathrm{DE} \mathrm{L} 2 / 3=6.2 \pm 6.2, p=0.0018 ; \mathrm{NR} \mathrm{L} 4=6.6$ \pm 6.7 , DE L4 = 9.6 \pm 7.9 ; Wilcoxon rank-sum test, $p<10^{-28}$ ). 
A Cell $1 \quad$ Cell 2

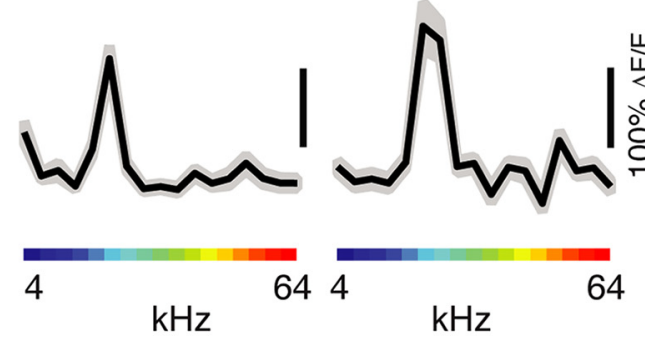

B Response amplitude
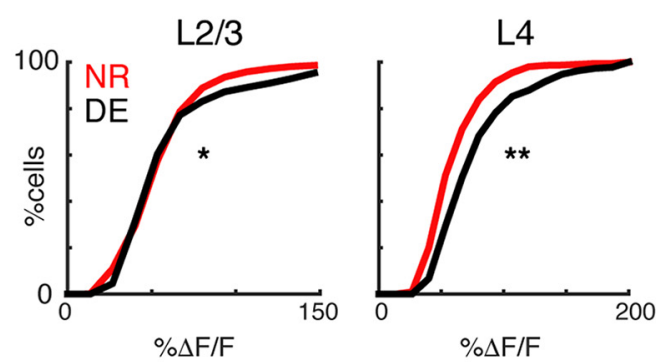

D Response amplitude
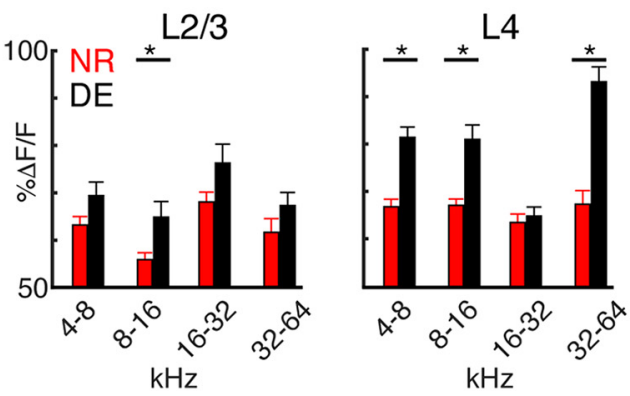

\section{Amplitude and Bandwidth}

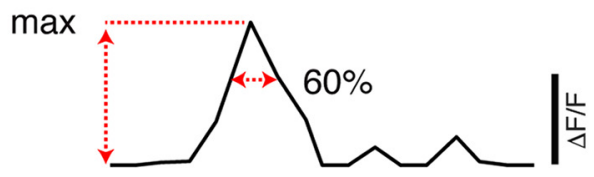

C

Bandwidth
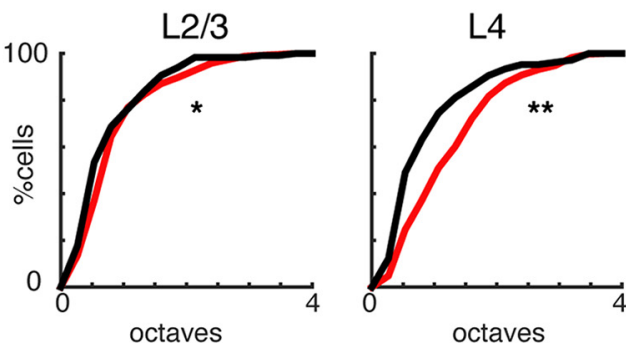

E

Bandwidth
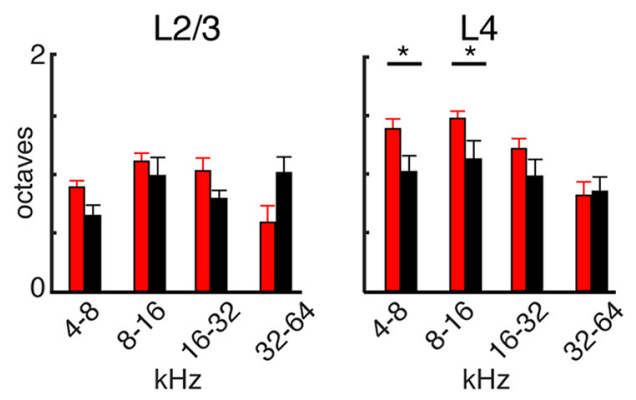

Figure 2. DE increases the responsiveness and frequency selectivity of neurons in both $L 4$ and $L 2 / 3$. $\boldsymbol{A}$, Exemplar tuning curves (mean $\pm 1.96 *$ SEM) of two cells obtained from tone evoked responses. $\boldsymbol{B}, \boldsymbol{C}$, Cumulative distribution functions of response amplitudes (B) and bandwidth. $\boldsymbol{B}$, Response amplitude measured by peak $\Delta \mathrm{F} / \mathrm{F}$ increased in L4 and L2/3 after DE [mean $\pm \mathrm{SEM}$, L4 NR $=65.9 \pm$ $0.9 \%, \mathrm{DE}=83.0 \pm 1.4 \%$; Kolmogorov-Smirnov (KS) test, $p<10^{-16}$; L2/3 NR $=61.3 \pm 1.0 \%, \mathrm{DE}=67.35 \pm 1.6 \%$; KS test, $p=$ 0.027]. C, Bandwidth decreased in L4 and L2/3 after DE (mean \pm SEM, L4 NR $=1.17 \pm 1.14$, DE $=0.68 \pm 0.79$ octaves; KS test, $p<10^{-5}$; L2/3: NR $=0.98 \pm 0.04$, DE $=0.86 \pm 0.06$, KS test; $\left.p=0.01\right)$. $\boldsymbol{D}, \boldsymbol{E}$, Response amplitudes $(\boldsymbol{D})$ and bandwidth $(\boldsymbol{E})$ in octave frequency bins. $\boldsymbol{E}$, Response amplitudes in L2/3 were increased for cells with BFs of $8-16 \mathrm{kHz}(4-8 \mathrm{kHz} p=0.066 ; 8-16 \mathrm{kHz} p=$ $0.004 ; 16-32 \mathrm{kHz} p=0.07 ; 32-64 \mathrm{kHz} p=0.32)$. Response amplitudes in L4 were increased for cells with BFs of 4-8, 8-16, and $32-64 \mathrm{kHz}\left(4-8 \mathrm{kHz} p=5.2 \times 10^{-8} ; 8-16 \mathrm{kHz} p=2.4 \times 10^{-6} ; 16-32 \mathrm{kHz} p=0.7 ; 32-64 \mathrm{kHz} p=1.4 \times 10^{-5}\right)$. D, Bandwidth in L2/3 was similar in each bin $(4-8 \mathrm{kHz} p=0.073 ; 8-16 \mathrm{kHz} p=0.45 ; 16-32 \mathrm{kHz} p=0.075 ; 32-64 \mathrm{kHz} p=0.089)$. Bandwidth in L4 was decreased for cells with BFs of $8-16$ and $16-32 \mathrm{kHz}(4-8 \mathrm{kHz} p=0.039 ; 8-16 \mathrm{kHz} p=0.029 ; 16-32 \mathrm{kHz} p=0.29 ; 32-64$ $\mathrm{kHz} p=0.86)$.

cells after DE as compared to cells from NR animals (Fig. $2 C)$ with a greater magnitude of decrease in L4 than L2/3. Together, these results show that on the single cell level, changes after DE are similar in both $\mathrm{L} 4$ and L2/3 with the exception that response amplitudes in L4 but not L2/3 increase after DE.

Thus, DE after the critical period can alter the sound evoked responses of $A 1$ neurons in both $L 4$ and L2/3 but the magnitude of changes might be greater in L4 than L2/3. Together, these results indicate that while fewer cells responded to tones after $\mathrm{DE}$, those cells that did respond to tones in $\mathrm{A} 1$ become more responsive and selective to sound after DE in both $L 4$ and $L 2 / 3$. These in vivo imaging results are consistent with prior microelectrode recordings in L4 (Petrus et al., 2014) and extend those prior observations to L2/3.

\section{DE alters the distribution of frequency selectivity in A1}

Our results indicate that tone-responsive cells in L4 of A1 showed higher response amplitude and cells in both layers of A1 showed increased selectivity to sound after $D E$. However, these changes on the single cell level do not explain why fewer responsive neurons exist in L2/3 after 
DE. Neurons in sensory cortices can adjust their tuning based on behavioral demands (Fritz et al., 2003, 2005; Polley et al., 2006; Winkowski et al., 2013; Francis et al., 2018). Moreover, early sensory experience can alter the amount of $A 1$ territory that responds to tones of a certain frequency (Zhang et al., 2001). We thus reasoned that it might be possible that as a population, cells shifted their stimulus preference. To explore the possibility of such a scenario, we investigated the distribution of preferred frequencies in NR and DE mice over the population of imaged cells. In microelectrode studies of A1 plasticity A1 is sparsely sampled, tessellated, and the relative areas of regions with certain BFs is calculated (Zhang et al., 2001). Since in vivo cellular imaging revealed that neighboring cells can show very different BFs (Bandyopadhyay et al., 2010; Rothschild et al., 2010; Winkowski and Kanold, 2013; Maor et al., 2016), we do not calculate the fractional A1 area but instead the fraction of A1 cells showing a certain BF. In NR animals, cells in both L4 and L2/3 showed preferred frequencies ranging from 4 to $64 \mathrm{kHz}$ with most neurons preferring tones between 8 and $32 \mathrm{kHz}$ (Fig. 3), consistent with the most sensitive area of mouse hearing and the overrepresentation of such frequencies in A1 (Stiebler et al., 1997; Guo et al., 2012; Liu et al., 2019). In contrast, DE mice showed an altered distribution of BFs with relatively more cells responding to high frequencies (32-64 kHz; Fig. 3B). Across animals, we observed an increase in the proportion of cells selective for high frequencies (32-64 kHz) in L2/3 and an increase in cells selective for low frequencies $(4-8 \mathrm{kHz})$ combined with decrease for mid-frequencies $(8-16 \mathrm{kHz})$ in L4 (Fig. $3 A$ ). Together, these results suggested that the functional representation of tones in $\mathrm{A} 1$ broadens after DE.

\section{DE decreases the pairwise activity correlations between neurons}

Sensory stimuli are not only encoded by single neurons but by populations of neurons, and activity correlations between neurons contribute to information encoding (Averbeck et al., 2006). In both L4 and L2/3, nearby cells show high SCs, which reflect stimulus-driven correlated activity, and NCs, which represent stimulus-independent, trial-to-trial covariance (Winkowski and Kanold, 2013). Pairwise correlations can serve as a proxy for functional connections with interconnected cells having increased NCs. Since our circuit analysis in DE animals showed a refinement of functional interlaminar and intralaminar connections (Meng et al., 2015, 2017a) we reasoned that pairwise correlations might decrease. We thus examined whether DE altered the level of correlated activity between neurons in $L 4$ and $L 2 / 3$ by calculating the pairwise correlation of neurons in the imaged field.

DE resulted in a decrease in both NC and SC between simultaneously imaged L4 cells (Fig. 4). However, in contrast to the effects in L4 NCs were largely unchanged in L2/3 (Fig. 5A). DE resulted in a decrease in SC between simultaneously imaged L2/3 cells (Fig. $5 B$ ). Together, these results show that $D E$ not only alters the tuning of single neurons in $L 4$ and $L 2 / 3$ but also the local activity relationships between neurons. The decreased pairwise correlations indicate a sparsification of the population activity in $\mathrm{A} 1$ consequent to $\mathrm{DE}$.

The changes in SCs and NCs after DE might differ depending on the BF relationships of the cell pair. We found that L4 NCs did not change after DE for cell pairs that were co-tuned and for cell pairs with different BFs (Fig. 6A). L4 SCs were higher between co-tuned cells and the decrease in L4 SC after DE occurred for both cotuned and non-co-tuned cells (Fig. 6B). We observed similar changes in L2/3 (Fig. 6C,D). These results indicate that the sparsification of responses consequent to $D E$ did not depend on the tuning relationship of neuronal pairs.

We next investigated whether changes in pairwise correlations were similar for cell pairs across the hearing range. We thus separately calculated pairwise correlations between cells with frequency preference in different octave bands (Fig. 7). In L4 DE decreased NCs and SCs for pairs of cells in the 4- to 8-, 8- to 16-, and 16- to $32-\mathrm{kHz}$ frequency groups but increased for cell pairs between 32 and $64 \mathrm{kHz}$ (Fig. 7A,B). In L2/3, DE increased NCs for pairs in 4- to 8- and 16- to $32-\mathrm{kHz}$ range, while SCs decreased for cells in 4- to 8- and 8- to $16-\mathrm{kHz}$ band (Fig. $7 C, D$ ). These results indicate that DE increases the number of cells responding to high frequencies and in addition also increases the pairwise correlations between L4 cells in high frequency bands while decreasing correlations elsewhere.

SCs are a measure of similarity between tuning curves of neurons, thus changes in SC could depend on the bandwidths of the neurons in a pair. For each cell pair we summed the bandwidth of each neuron and plotted the $\mathrm{NC}$ and $\mathrm{SC}$ as a function of bandwidth sum in octaves (Fig. 8A,B). There was no dependence of $\mathrm{NC}$ and $\mathrm{SC}$ on bandwidth sum in NR mice. After DE cell pairs with intermediate bandwidth sum in both $L 4$ and L2/3 showed decreased SC (Fig. 8B,D) indicating that DE causes reduced SCs for neuronal pairs with intermediate or mismatched bandwidths (either one narrow and one broad or both moderate). In L2/3 neuronal pairs, NCs increased for pairs with broad bandwidth sums (Fig. 8C). Together, these results indicate that DE had the largest effect on SCs between neurons with intermediate combined bandwidth. This suggests that the change in correlations after $\mathrm{DE}$ is not solely due to changes in bandwidth but also due to changes in the relative tuning by cells in the imaged fields.

\section{Discussion}

Using in vivo two-photon $\mathrm{Ca}^{2+}$ imaging we show that brief $(7 \mathrm{~d})$ periods of visual deprivation in adult mice resulted in robust cross-modal changes in population activity of thalamorecipient and supragranular layers of A1.

On the single cell level, we find that DE after the critical period can alter both spontaneous and sound-evoked responses of $A 1$ neurons in both $L 4$ and L2/3. Specifically, after DE, cells show increased spontaneous activity in both layers, increased responsive amplitudes and decreased bandwidth in both L4 and L2/3. These changes after DE in L4 are consistent with prior microelectrode 
A L4 BF distribution
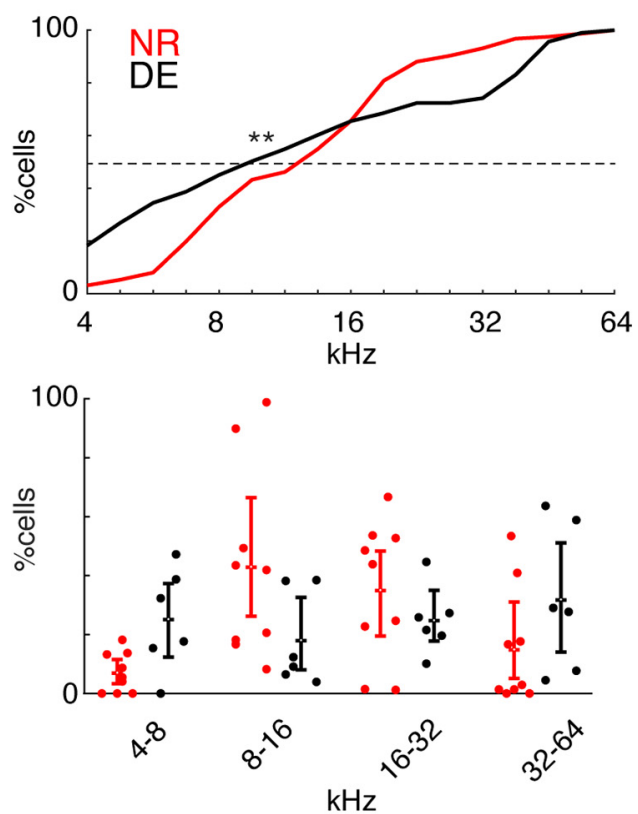

$\Delta$ (DE-NR)

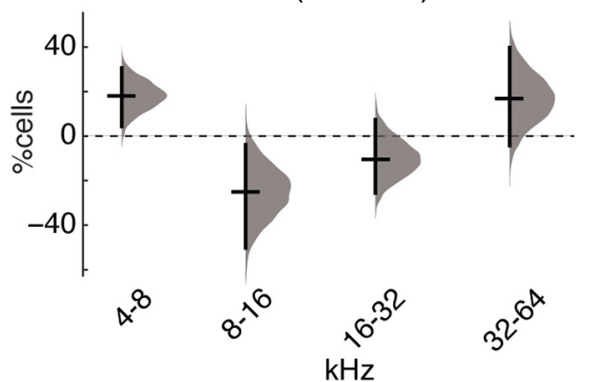

B L2/3 BF distribution
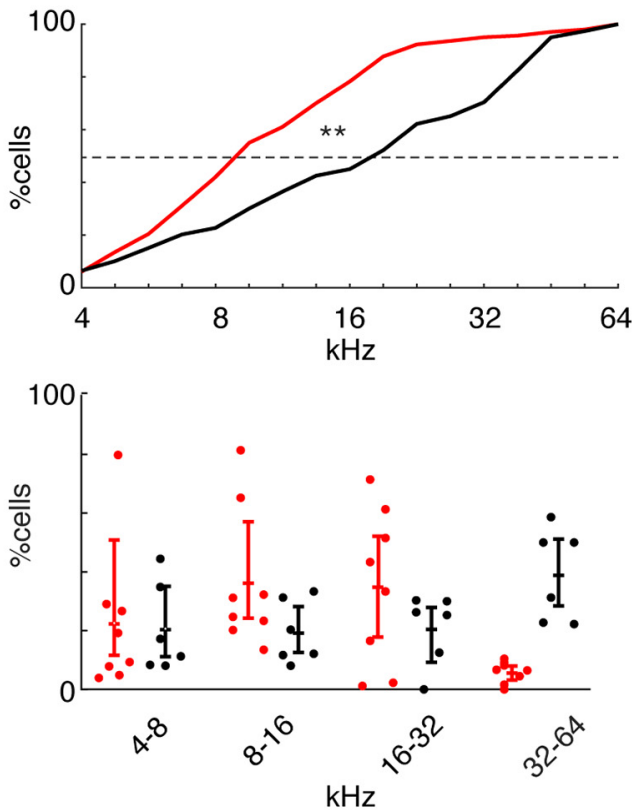

$\Delta$ (DE-NR)

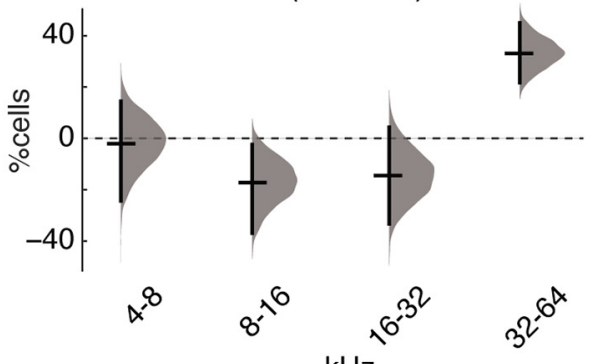

$\mathrm{kHz}$

Figure 3. DE alters the representation of sound frequencies in A1. Distribution of BFs in NR and DE in all imaging fields from L4 (A) and L2/3 (B) and across mice (Table 1). $\boldsymbol{A}$, top panel, Cumulative distributions showing the spread of BFs in NR (red) and DE (black) in imaging fields from L4. The BF distribution of cells differs between DE and NR [Kolmogorov-Smirnov (KS) test; L4 $p<10^{-23}$ ]. Lower panels, Same data as in top panel by animals (nine mice NR; six mice DE) and binned into octaves. The mean differences for the comparisons are shown by Cumming estimation plot. The raw data are plotted on the upper axes; summary measurements (mean \pm SD) are shown as lines. Mean differences for each frequency bin are plotted on the lower plot as a bootstrap sampling distribution (DABEST). Mean differences are depicted as horizontal lines; 95\% confidence intervals are indicated by the ends of the vertical error bars $(4-8 \mathrm{kHz}: 18.2 \%$ [95.0\% Cl, 4.34, 30.7], $p=0.0432 \mathrm{Mann}-$ Whitney; 8-16 kHz: $-24.9 \%[95.0 \% \mathrm{Cl}-50.2,-3.86], p=0.0518$; $16-32 \mathrm{kHz}:-10.2 \%[95.0 \% \mathrm{Cl},-25.5,7.41], p=0.377 ; 32-64 \mathrm{kHz}: 17 \%[95.0 \% \mathrm{Cl},-4.21,39.8], p=0.0872)$. Effect size [Cl width, lower bound, upper bound]. $\boldsymbol{B}$, top panel, Cumulative distributions showing the spread of BFs in NR (red) and DE (black) in imaging fields from L2/3. The BF distribution of cells differs between DE and NR (KS test; L2/3 $p<10^{-40}$ ). Lower panels, Same data as in top panel by animals (eight mice NR; six mice DE) and binned into octaves. The mean differences for the comparisons are shown by Cumming estimation plot. Mean differences are depicted as in $\boldsymbol{A}(4-8 \mathrm{kHz}: 1.8 \%$ [95.0\% Cl, $-24.3,14.4], p=0.651 \mathrm{Mann}-\mathrm{Whitney}$; $8-16 \mathrm{kHz}:-17.1 \%$ [95.0\% $\mathrm{Cl},-26.9,2.41], p=0.175 ; 16-32 \mathrm{kHz}:-14.3 \%$ [95.0\% $\mathrm{Cl},-33.3,4.33], p=0.22 ; 32-64 \mathrm{kHz}: 32.28 \%$ [95.0\% $\mathrm{Cl}, 21.68,44.99], p=0.0024)$.

studies of L4 (Petrus et al., 2014) and we here extend those findings to L2/3. Increase in spontaneous activity is reminiscent of changes seen after within modality sensory deprivation, which seems to correlate with engagement of cortical plasticity. For example, spontaneous firing rate is increased in A1 following noise-induce hearing loss (Komiya and Eggermont, 2000; Seki and Eggermont, 2003) and in V1 after a few days of DE (Bridi et al., 2018). In the case of within modality sensory deprivation, it is likely driven by a decrease in feedforward inhibition by loss of sensory drive, as well as a decrease in inhibitory synaptic function (Gao et al., 2014, 2017). However, this is unlikely to be the case for cross-modal sensory deprivation. To the contrary, we reported that inhibitory synaptic transmission increases in $\mathrm{A} 1 \mathrm{~L} 4$ and $\mathrm{L} 2 / 3$ following $\mathrm{DE}$ (Petrus et al., 2015). This is similar to increased inhibition following cross-modal rewiring of $\mathrm{A} 1$ (Mao and Pallas, 2013). It is plausible that cross-modal deprivation may lead to temporary disinhibition similar to what is describe for within modality sensory deprivation (Kuhlman et al., 
A
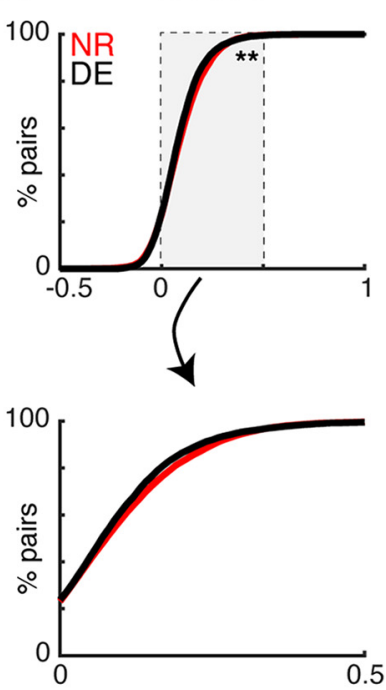

c $\triangle$ CDF NR-DE

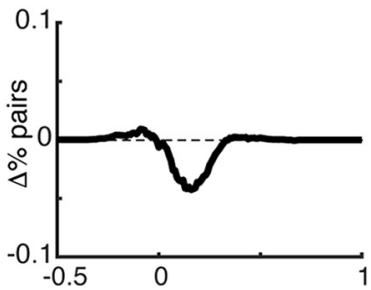

B
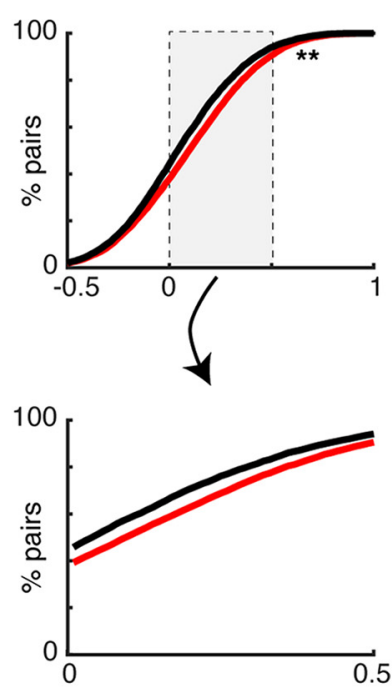

D $\quad \triangle$ CDF NR-DE

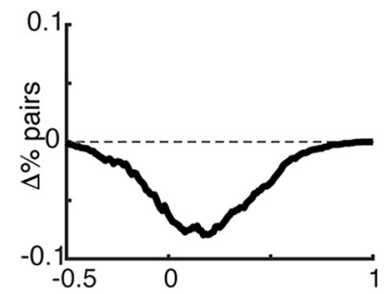

A
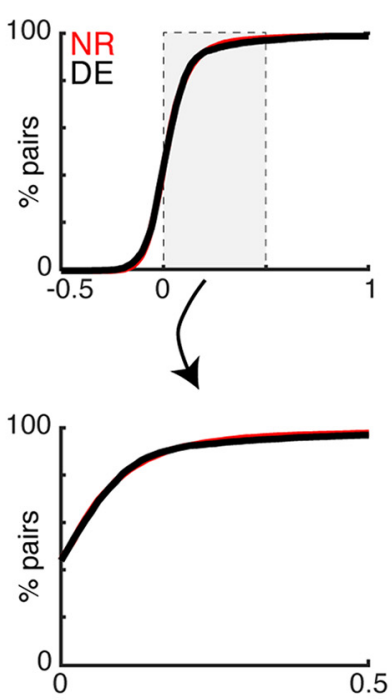

c $\triangle$ CDF NR-DE

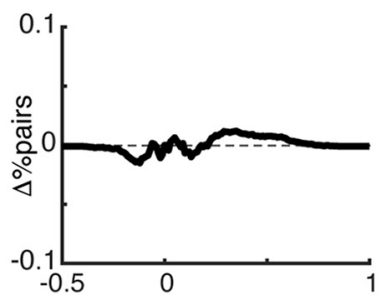

B
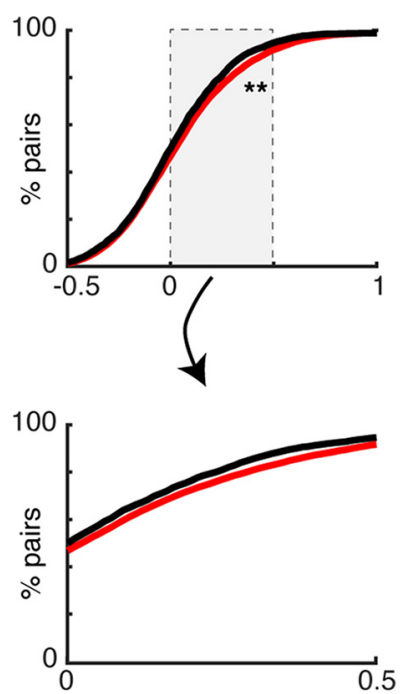

D $\triangle$ CDF NR-DE

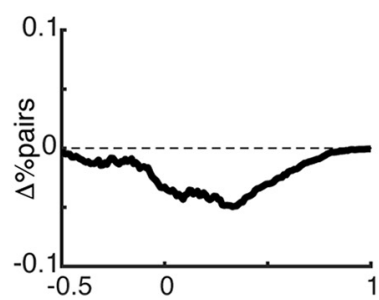

Figure 4. DE decreases pairwise activity correlations in L4. $\boldsymbol{A}, \boldsymbol{B}$, CDFs of pairwise noise (NC) and signal correlations (SC) in L4 from NR and DE animals [Kolmogorov-Smirnov (KS) test; L4 NC $p=3.7 \times 10^{-4} ;$ L4 SC $\left.p=6.5 \times 10^{-28}\right]$. Lower panels show magnified view of center of distributions. $\boldsymbol{C}, \boldsymbol{D}$, Differences between the CDFs show a broad decrease in SC in L4.

2013), which is thought to enable plasticity. However, at a later time point inhibition may be increased to consolidate the changes. We previously found that DE reduces neuronal thresholds (Petrus et al., 2014). Since we used a fixed sound level, cells in DE were tested at a relative sound level that was slightly higher compared to threshold than in cells in NR. As bandwidth increases with sound level for most auditory neurons, our results might underestimate the decrease in bandwidth after DE.

Our results corroborate that increased spontaneous activity correlates with cortical plasticity. In vivo crossmodal changes on the single cell level are also consistent with prior in vitro studies which have shown extensive synaptic and circuit level changes in both L4 and L2/3 (Petrus et al., 2014, 2015; Meng et al., 2015, 2017a). However, our results further indicate that changes in sound-evoked properties are larger in $L 4$ than $L 2 / 3$, which suggests that previously observed potentiation of TC synapses (Petrus et al., 2014) and recurrent L4 excitatory inputs (Petrus et al., 2015) may play a prominent role in sculpting A1 functionality. While it is conceivable that anesthesia obscures even more extensive circuit changes in $L 2 / 3$, we speculate that since the pure-tone bandwidth of $L 2 / 3$ cells is already narrower than that of $L 4$ neurons (Winkowski and Kanold, 2013), DE might alter other fea-

Figure 5. DE decreases pairwise activity correlations in $\mathrm{L} 2 / 3 . \boldsymbol{A}$, $\boldsymbol{B}, \mathrm{CDFs}$ of pairwise noise (NC) and signal correlations (SC) in L2/3 from NR and DE [Kolmogorov-Smirnov (KS) test; L2/3 NC $p$ $=0.37$; L2/3 SC $p=7.7 \times 10^{-9}$ ]. Lower panels show magnified view of the center of distributions. $\boldsymbol{C}, \boldsymbol{D}$, Differences between the CDFs show a broad decrease in SCs in L2/3.

tures of the cells' receptive field which are not revealed with pure tones such as spectral contrast sensitivity (Barbour and Wang, 2003). Furthermore, synaptic circuit changes in A1 L2/3 are rather complex compared to those seen in L4. For example, in addition to potentiation of feedforward synapses from L4, there is large scale depression of lateral inputs within L2/3 (Petrus et al., 2015), as well as refinement of both inputs (Meng et al., 2015). Hence functional consequence of DE on A1 L2/3 function is difficult to predict. Regardless, our results suggest that $D E$ induced functional adaptation of A1 L2/3 circuits may be geared toward expanding representation of higher frequency tones and sparsification of population coding.

In vivo two-photon $\mathrm{Ca}^{2+}$ imaging also allows us to identify population and network level changes after DE. After $\mathrm{DE}$, we observe a decrease in pairwise correlations between neurons in both $L 4$ and $L 2 / 3$ but a selective increase for pairs of cells tuned to $32-64 \mathrm{kHz}$. Since SCs are reflective of stimulus-carrying inputs and since thalamocortical inputs drive L4 neurons, our observed decrease in L4 SCs suggests a refinement of thalamocortical input to L4 neurons after DE. This would be consistent with the observation of decreased bandwidth and increase responses of L4 neurons after DE (Petrus et al., 
A

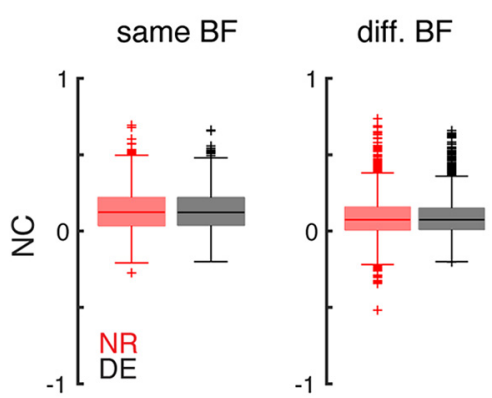

C L2/3 Noise Correlation same BF

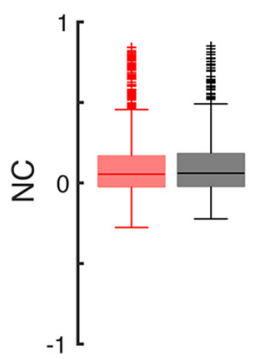

diff. BF

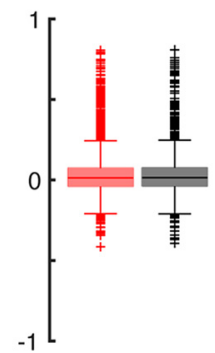

\section{B L4 Signal Correlation}

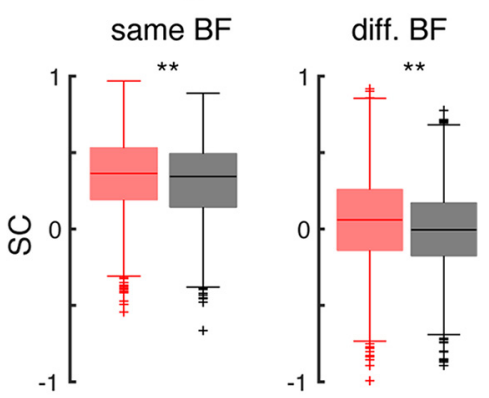

D L2/3 Signal Correlation

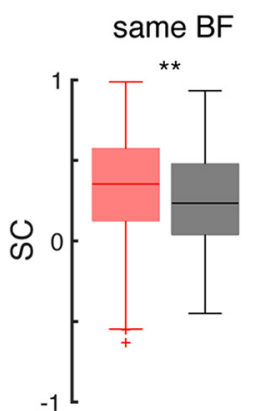

Figure 6. DE decreases pairwise SCs for both co-tuned and non-co-tuned neurons. $\boldsymbol{A}$, L4 NCs in NR and DE for cells with similar and different BF $(p=0.95 ; p=0.97)$. B, L4 SCs in NR and DE for cells with similar and different BF $\left(p<0.0036 ; p=5.4 \times 10^{-35}\right)$. C, L2/3 NCs in NR and DE for cells with similar and different BF ( $p=0.37 ; p=0.96)$. $D, L 2 / 3$ SCs in NR and DE for cells with similar and different BF $\left(p<1.2 \times 10^{-5} ; p<0.0094\right)$.

2014). Since in vitro data showed a strengthening of thalamocortical synapses (Petrus et al., 2014) our results suggest that DE after the critical period leads to both a refinement and strengthening of thalamocortical synapses. On the other hand, NCs can be reflective of intracortical connections. The observed decrease in NC in L4 after DE is consistent with changes in interlaminar connections to L4 (Meng et al., 2017a). In L2/3 we also observe overall decreased SCs, suggesting that ascending connections from L4 refine consistent with in vitro observations (Meng et al., 2015) and also with increased mIPSCs frequency (Petrus et al., 2015) indicating increased inhibitory tone. We did not find changes in L2/3 NC except for small increases in 4- to 8- and 16- to $32-\mathrm{kHz}$ pairs. NCs likely reflect the extensive intralaminar connectivity of L2/3 neurons (Atzori et al., 2001; Levy and Reyes, 2012; Meng et al., 2017b), thus the lack of consistent change in NCs would suggest no changes in intralaminar connectivity. However, prior laser-scanning photostimulation (LSPS) studies suggested that intra-L2/3 circuits refine following DE (Meng et al., 2015). The difference might be due to the limited spatial resolution of LSPS, which does not allow investigation of connections within the $100-\mu \mathrm{m}$ range that was included in our current study.

After DE, single neurons show higher spontaneous and sound-evoked responses in both layers. However, this increase in firing rates did not cause a general increase in pairwise activity correlations except for pairs in the 32- to $64-\mathrm{kHz}$ band. This suggests that activity correlations can be independently controlled, possibly via selective en- gagement of inhibitory circuits. Indeed, both excitatory and inhibitory circuits to L4 neurons change after DE (Petrus et al., 2015; Meng et al., 2017a). Changes in activity correlations are also seen after noise exposure during the critical period and after and changes in inhibition might underlie this change (Zhang et al., 2002; Zhou and Merzenich, 2012).

Feedforward projections determine the initial tuning preference of neurons and maintain tonotopy on a coarse scale, whereas intracortical inputs can either broaden spectral tuning via excitatory synapses, or sharpen receptive fields via inhibitory inputs (Wehr and Zador, 2003; Kaur et al., 2004, 2005; Tan et al., 2004; Wu et al., 2008; Happel et al., 2010). Feed-forward projections from the medial geniculate body (MGB) of the thalamus determine the frequency preference of L4 neurons (Li et al., 2013). We here observed a decrease in SCs in L4. The decrease in SCs in L4 suggests that after DE, MGB inputs to L4 cells are refined, either by changing the sets of frequency inputs or the strength of these inputs to neighboring L4 cells. Alternatively, intracortical inputs to L4 neurons could have changed. Indeed, in vitro circuit mapping studies have shown that L2/3-L4 connections but not L4-L4 connections refine after DE (Meng et al., 2017a). Thus, feedback projections from L2/3 could contribute to the adjustment of the spatial representation of sound frequency in L4.

While we observed a decrease in SCs in both L4 and $L 2 / 3$, the magnitude of these changes was larger in $L 4$ than $L 2 / 3$. This could indicate a ceiling effect signifying a minimum in SCs because SCs are larger in L4 than L2/3 
A

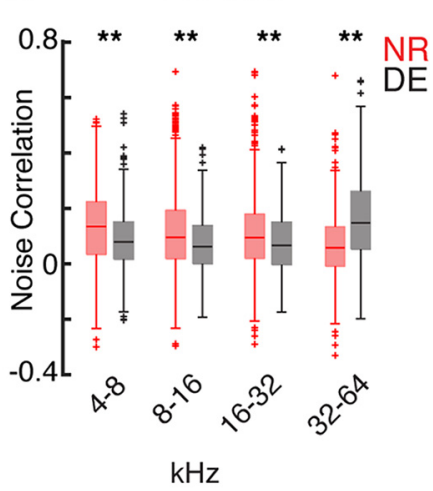

C

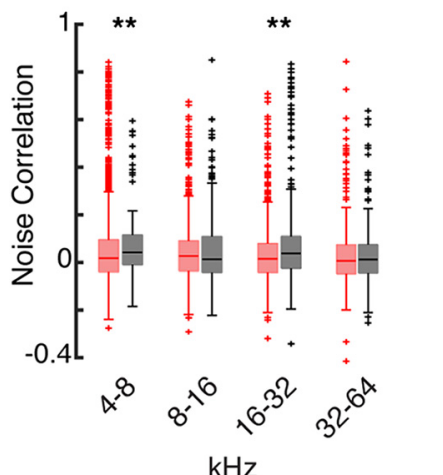

B

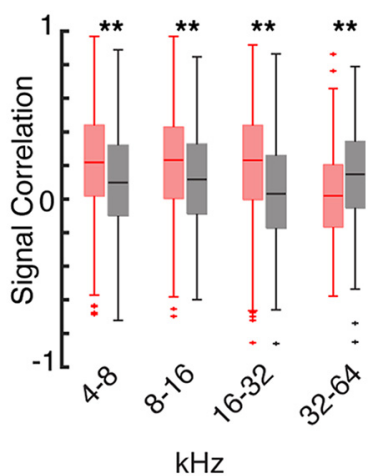

D

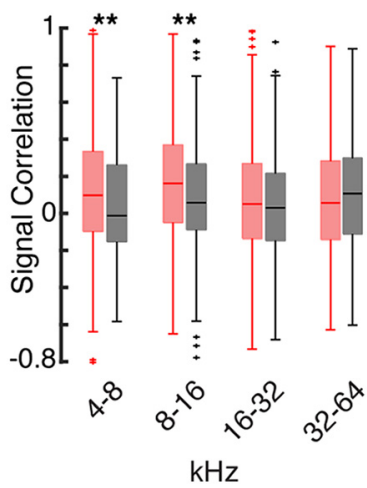

Figure 7. DE causes frequency specific effects on SCs and NCs. $\boldsymbol{A}$, Boxplots showing NCs for L4 cell pairs with BFs of $4-8,8-16$, $16-32$, and $32-64 \mathrm{kHz}$ from NR and DE $\left(p=7.3 \times 10^{-18}, p=\right.$ $\left.1.2 \times 10^{-10}, p=8.3 \times 10^{-5}, p=1.9 \times 10^{-22}\right)$. B. Boxplots showing SCs for L4 cell pairs with BFs of $4-8,8-16,16-32$, and $32-64 \mathrm{kHz}$ from NR and DE $\left(p=7.5 \times 10^{-17}, p=4.4 \times 10^{-12}\right.$, $\left.p=5.4 \times 10^{-20}, p=8.38 \times 10^{-10}\right) . C$, Boxplots showing NCs for $L 2 / 3$ cell pairs with BFs of $4-8,8-16,16-32$, and $32-64 \mathrm{kHz}$ from NR and DE $(p=0.006, p=0.48, p=0.0004, p=0.73)$. $\boldsymbol{D}$, Boxplots showing SCs for $L 2 / 3$ cell pairs with BFs of $4-8,8-16$, $16-32$, and $32-64 \mathrm{kHz}$ from NR and DE $(p=0.002, p=0.0001$, $p=0.22, p=0.16)$.

(Winkowski and Kanold, 2013). Alternatively, these results could indicate that a certain level of population response sparsification is maintained. Since $L 2 / 3$ receives its dominant ascending input from $\mathrm{L} 4$ and since intracortical circuits to both L4 and L2/3 change after DE (Meng et al., 2015, 2017a; Petrus et al., 2015), this could suggest that L4-L2/3 circuit refinement after DE might normalize the frequency representation.

Our results also show that DE induces a decorrelation of the sound evoked population activity in A1. Decorrelation of sensory responses can lead to increased encoding fidelity of represented stimuli (Averbeck et al., 2006) and our prior studies of $\mathrm{A} 1$ have shown that decorrelation can improve discrimination performance (Winkowski et al., 2013) and that engagement in tone detection tasks can lead to temporary decorrelation of A1 responses during trials (Francis et al., 2018). Thus, we speculate that a period of DE in which animals rely on sound and not vision might cement these temporary changes.
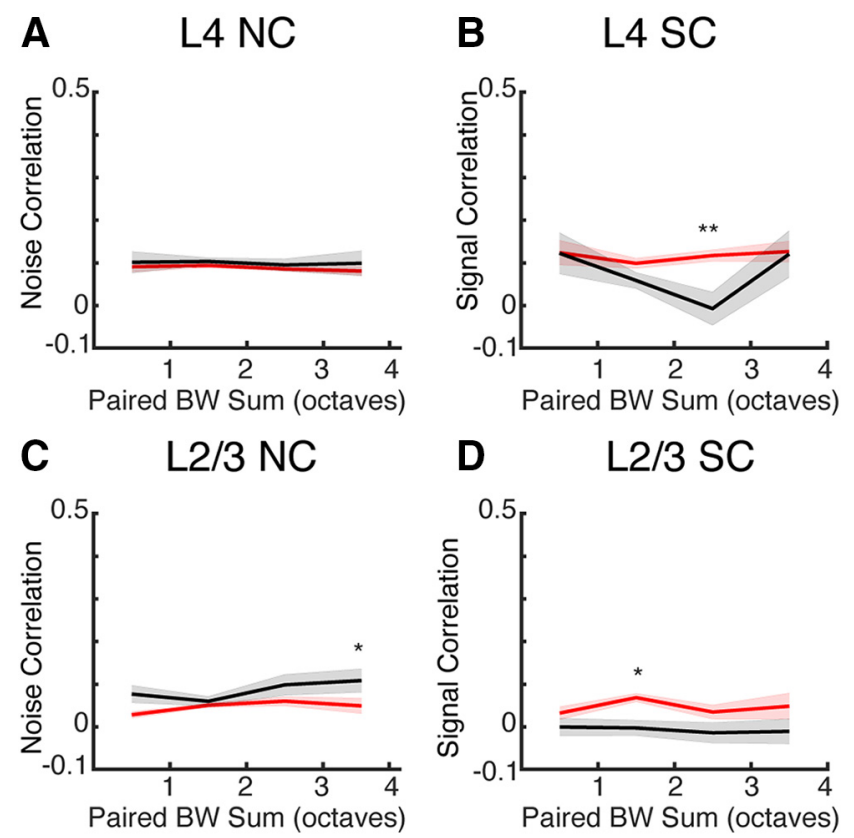

Figure 8. DE-induced changes in pairwise correlations can depend on bandwidth sum. $\boldsymbol{A}, \mathrm{NCs}$ for $\mathrm{L} 4$ cell pairs as a function of summed bandwidth from NR and DE. $B$, SCs for L 4 cell pairs as a function of summed bandwidth from NR and DE from NR and DE (** indicates significant difference at $p<0.01$ ). $C$, NCs for $L 2 / 3$ cell pairs as a function of summed bandwidth from NR and $\mathrm{DE}$ (* indicates significant difference at $p<0.05$ ). $\boldsymbol{D}$, SCs for $\mathrm{L} 2 / 3$ cell pairs as a function of summed bandwidth from NR and DE $(*$ indicates significant difference at $p<0.05$ ).

After DE, a lower fraction of neurons in both layers are selective for mid-frequencies and a relatively higher fraction of cells are selective for high-frequencies. While these changes could be due to a sampling bias in our experiments, we sampled many fields across A1 (Table 1) making such systematic differences unlikely. Rather, it is more probable that DE has changed the representation of sound in A1. Moreover, we find that while overall SCs decreased after DE, pairs within the $32-$ to $64-\mathrm{kHz}$ frequency range increased their SCs indicating a differential effect on low-frequency and high-frequency cells. The increase in SC for cells in the 32- to 64-kHz range points to a selective effect of DE on high-frequency cells. A1 neurons can adapt to stimulus statistics by decreasing responsiveness to frequently occurring sounds (Ulanovsky et al., 2003; Nelken, 2004, 2014; Winkowski et al., 2013; Pérez-González and Malmierca, 2014). We speculate that these changes reflect, and are dependent on, the sound experience of the animal during DE. While we have previously not detected any differences in the sound environment in NR and DE, we did find that animal vocalizations under our conditions are most frequent in the mid-frequency range (Petrus et al., 2014). However, besides vocalizations, animals are exposed to a variety of other ambient or self-generated sounds (e.g., from locomotion). While ambient sound level was similar in DE and NR, we did not compare the ambient sound spectrum during the housing period nor did we observe the behavior of the animals during NR and DE. Thus, it is 
possible that other sounds besides vocalization differed between NR and DE.

Despite the caveats, we speculate that DE amplifies adaptive processes leading to changes in synaptic strength that reflect the sound environment, consistent with our observation of decorrelation of responses. It is tempting to conjecture that pairing the presence of specific sound stimuli with DE might be able to drive targeted changes in A1. Consistent with this idea, cross-modal sensory deprivation has been shown to facilitate LTP in V1 (Rodríguez et al., 2018).

Recent studies revealed that A1 responses sparsify with development and that auditory experience early in life can shape this process (Liang et al., 2019; Meng et al., 2019). We here show that visual experience later in life has a similar capability. Our results reveal changes in the population activity and frequency organization of $A 1$ well after the critical period, suggesting that cross-modal plasticity of A1 circuits may underlie the improvements in auditory perception in humans following vision loss (Lessard et al., 1998; Röder et al., 1999; Gougoux et al., 2004; Voss et al., 2004). These results add to the mounting evidence that experience-dependent plasticity is not restricted to early developmental windows, and that crossmodal sensory experience has the power to alter network circuitry and population dynamics even into adulthood. Thus, it might be possible to harness this environmental manipulation to restore function lost as a result of impaired developmental experiences, and consistent with this, a brief duration of auditory or whisker deprivation is able to restore ocular dominance plasticity in adult V1 (Rodríguez et al., 2018; Teichert et al., 2018, 2019).

\section{References}

Atzori M, Lei S, Evans DI, Kanold PO, Phillips-Tansey E, Mclntyre O, McBain CJ (2001) Differential synaptic processing separates stationary from transient inputs to the auditory cortex. Nat Neurosci 4:1230-1237.

Averbeck BB, Latham PE, Pouget A (2006) Neural correlations, population coding and computation. Nat Rev Neurosci 7:358-366.

Bandyopadhyay S, Shamma SA, Kanold PO (2010) Dichotomy of functional organization in the mouse auditory cortex. Nat Neurosci 13:361-368.

Barbour DL, Wang X (2003) Contrast tuning in auditory cortex. Science 299:1073-1075.

Barkat TR, Polley DB, Hensch TK (2011) A critical period for auditory thalamocortical connectivity. Nat Neurosci 14:1189-1194.

Bridi MCD, de Pasquale R, Lantz CL, Gu Y, Borrell A, Choi SY, He K, Tran T, Hong SZ, Dykman A, Lee HK, Quinlan EM, Kirkwood A (2018) Two distinct mechanisms for experience-dependent homeostasis. Nat Neurosci 21:843-850.

Chen Q, Cichon J, Wang W, Qiu L, Lee SJ, Campbell NR, Destefino N, Goard MJ, Fu Z, Yasuda R, Looger LL, Arenkiel BR, Gan WB, Feng G (2012) Imaging neural activity using Thy1-GCaMP transgenic mice. Neuron 76:297-308.

Dana H, Chen TW, Hu A, Shields BC, Guo C, Looger LL, Kim DS, Svoboda K (2014) Thy1-GCaMP6 transgenic mice for neuronal population imaging in vivo. PLoS One 9:e108697.

de Villers-Sidani E, Chang EF, Bao S, Merzenich MM (2007) Critical period window for spectral tuning defined in the primary auditory cortex (A1) in the rat. J Neurosci 27:180-189.

Dorr A, Sled JG, Kabani N (2007) Three-dimensional cerebral vasculature of the CBA mouse brain: a magnetic resonance imaging and micro computed tomography study. Neuroimage 35:14091423.

Francis NA, Winkowski DE, Sheikhattar A, Armengol K, Babadi B, Kanold PO (2018) Small networks encode decision-making in primary auditory cortex. Neuron 97:885-897.e6.

Fritz J, Shamma S, Elhilali M, Klein D (2003) Rapid task-related plasticity of spectrotemporal receptive fields in primary auditory cortex. Nat Neurosci 6:1216-1223.

Fritz J, Elhilali M, Shamma S (2005) Active listening: task-dependent plasticity of spectrotemporal receptive fields in primary auditory cortex. Hear Res 206:159-176.

Gao M, Maynard KR, Chokshi V, Song L, Jacobs C, Wang H, Tran T, Martinowich K, Lee HK (2014) Rebound potentiation of inhibition in juvenile visual cortex requires vision-induced BDNF expression. J Neurosci 34:10770-10779.

Gao M, Whitt JL, Huang S, Lee A, Mihalas S, Kirkwood A, Lee HK (2017) Experience-dependent homeostasis of 'noise' at inhibitory synapses preserves information coding in adult visual cortex. Philos Trans R Soc Lond B Biol Sci 372.

Goel A, Jiang B, Xu LW, Song L, Kirkwood A, Lee HK (2006) Cross-modal regulation of synaptic AMPA receptors in primary sensory cortices by visual experience. Nat Neurosci 9:1001-1003.

Gougoux F, Lepore F, Lassonde M, Voss P, Zatorre RJ, Belin P (2004) Neuropsychology: pitch discrimination in the early blind. Nature 430:309.

Guo W, Chambers AR, Darrow KN, Hancock KE, Shinn-Cunningham BG, Polley DB (2012) Robustness of cortical topography across fields, laminae, anesthetic states, and neurophysiological signal types. J Neurosci 32:9159-9172.

Happel MF, Jeschke M, Ohl FW (2010) Spectral integration in primary auditory cortex attributable to temporally precise convergence of thalamocortical and intracortical input. J Neurosci 30:1111411127.

Hubel DH, Wiesel TN (1970) The period of susceptibility to the physiological effects of unilateral eye closure in kittens. J Physiol 206:419-436.

Kalmbach AS, Waters J (2012) Brain surface temperature under a craniotomy. J Neurophysiol 108:3138-3146.

Kanold PO, Nelken I, Polley DB (2014) Local versus global scales of organization in auditory cortex. Trends Neurosci 37:502-510.

Kaur S, Lazar R, Metherate R (2004) Intracortical pathways determine breadth of subthreshold frequency receptive fields in primary auditory cortex. J Neurophysiol 91:2551-2567.

Kaur S, Rose HJ, Lazar R, Liang K, Metherate R (2005) Spectral integration in primary auditory cortex: laminar processing of afferent input, in vivo and in vitro. Neuroscience 134:1033-1045.

Kerlin AM, Andermann ML, Berezovskii VK, Reid RC (2010) Broadly tuned response properties of diverse inhibitory neuron subtypes in mouse visual cortex. Neuron 67:858-871.

King AJ, Parsons CH (1999) Improved auditory spatial acuity in visually deprived ferrets. Eur J Neurosci 11:3945-3956.

Komiya H, Eggermont JJ (2000) Spontaneous firing activity of cortical neurons in adult cats with reorganized tonotopic map following pure-tone trauma. Acta Otolaryngol 120:750-756.

Kuhlman SJ, Olivas ND, Tring E, Ikrar T, Xu X, Trachtenberg JT (2013) A disinhibitory microcircuit initiates critical-period plasticity in the visual cortex. Nature 501:543-546.

Lessard N, Paré M, Lepore F, Lassonde M (1998) Early-blind human subjects localize sound sources better than sighted subjects. Nature 395:278-280.

Levy RB, Reyes AD (2012) Spatial profile of excitatory and inhibitory synaptic connectivity in mouse primary auditory cortex. J Neurosci 32:5609-5619.

Li LY, Li YT, Zhou M, Tao HW, Zhang LI (2013) Intracortical multiplication of thalamocortical signals in mouse auditory cortex. Nat Neurosci 16:1179-1181.

Liang F, Li H, Chou XL, Zhou M, Zhang NK, Xiao Z, Zhang KK, Tao HW, Zhang LI (2019) Sparse representation in awake auditory cortex: cell-type dependence, synaptic mechanisms, developmental emergence, and modulation. Cereb Cortex 29:3796-3812. 
Liu J, Whiteway MR, Sheikhattar A, Butts DA, Babadi B, Kanold PO (2019) Parallel processing of sound dynamics across mouse auditory cortex via spatially patterned thalamic inputs and distinct areal intracortical circuits. Cell Rep 27:872-885.e7.

Mao YT, Pallas SL (2013) Cross-modal plasticity results in increased inhibition in primary auditory cortical areas. Neural Plast 2013: 530651.

Maor I, Shalev A, Mizrahi A (2016) Distinct spatiotemporal response properties of excitatory versus inhibitory neurons in the mouse auditory cortex. Cereb Cortex 26:4242-4252.

Meng X, Kao JP, Lee HK, Kanold PO (2015) Visual deprivation causes refinement of intracortical circuits in the auditory cortex. Cell Rep 12:955-964.

Meng X, Kao JP, Lee HK, Kanold PO (2017a) Intracortical circuits in thalamorecipient layers of auditory cortex refine after visual deprivation. eNeuro 4.

Meng X, Winkowski DE, Kao JPY, Kanold PO (2017b) Sublaminar subdivision of mouse auditory cortex layer $2 / 3$ based on functional translaminar connections. J Neurosci 37:10200-10214.

Meng X, Solarana K, Bowen Z, Liu J, Nagode DA, Sheikh A, Winkowski DE, Kao JPY, Kanold PO (2019) Transient subgranular hyperconnectivity to L2/3 and enhanced pairwise correlations during the critical period in the mouse auditory cortex. Cereb Cortex pii: bhz213.

Nelken I (2004) Processing of complex stimuli and natural scenes in the auditory cortex. Curr Opin Neurobiol 14:474-480.

Nelken I (2014) Stimulus-specific adaptation and deviance detection in the auditory system: experiments and models. Biol Cybern 108:655-663.

Pagé S, Sharp A, Landry SP, Champoux F (2016) Short-term visual deprivation can enhance spatial release from masking. Neurosci Lett 628:167-170.

Pérez-González D, Malmierca MS (2014) Adaptation in the auditory system: an overview. Front Integr Neurosci 8:19.

Peron SP, Freeman J, Iyer V, Guo C, Svoboda K (2015) A cellular resolution map of barrel cortex activity during tactile behavior. Neuron 86:783-799.

Petrus E, Isaiah A, Jones AP, Li D, Wang H, Lee HK, Kanold PO (2014) Crossmodal induction of thalamocortical potentiation leads to enhanced information processing in the auditory cortex. Neuron 81:664-673.

Petrus E, Rodriguez G, Patterson R, Connor B, Kanold PO, Lee HK (2015) Vision loss shifts the balance of feedforward and intracortical circuits in opposite directions in mouse primary auditory and visual cortices. J Neurosci 35:8790-8801.

Polley DB, Steinberg EE, Merzenich MM (2006) Perceptual learning directs auditory cortical map reorganization through top-down influences. J Neurosci 26:4970-4982.

Rauschecker JP, Kniepert U (1994) Auditory localization behaviour in visually deprived cats. Eur J Neurosci 6:149-160.

Röder B, Teder-Sälejärvi W, Sterr A, Rösler F, Hillyard SA, Neville HJ (1999) Improved auditory spatial tuning in blind humans. Nature 400:162-166.

Rodríguez G, Chakraborty D, Schrode KM, Saha R, Uribe I, Lauer AM, Lee HK (2018) Cross-modal reinstatement of thalamocortical plasticity accelerates ocular dominance plasticity in adult mice. Cell Rep 24:3433-3440.e4.

Rothschild G, Nelken I, Mizrahi A (2010) Functional organization and population dynamics in the mouse primary auditory cortex. Nat Neurosci 13:353-360.
Rothschild G, Cohen L, Mizrahi A, Nelken I (2013) Elevated correlations in neuronal ensembles of mouse auditory cortex following parturition. J Neurosci 33:12851-12861.

Sanes DH, Bao S (2009) Tuning up the developing auditory CNS. Curr Opin Neurobiol 19:188-199.

Seki S, Eggermont JJ (2003) Changes in spontaneous firing rate and neural synchrony in cat primary auditory cortex after localized tone-induced hearing loss. Hear Res 180:28-38.

Stiebler I, Neulist R, Fichtel I, Ehret G (1997) The auditory cortex of the house mouse: left-right differences, tonotopic organization and quantitative analysis of frequency representation. J Comp Physiol A Neuroethol Sens Neural Behav Physiol 181:559-571.

Suter BA, O'Connor T, lyer V, Petreanu LT, Hooks BM, Kiritani T, Svoboda K, Shepherd GM (2010) Ephus: multipurpose data acquisition software for neuroscience experiments. Front Neural Circuits 4:100.

Tan AY, Zhang LI, Merzenich MM, Schreiner CE (2004) Tone-evoked excitatory and inhibitory synaptic conductances of primary auditory cortex neurons. J Neurophysiol 92:630-643.

Teichert M, Isstas M, Zhang Y, Bolz J (2018) Cross-modal restoration of ocular dominance plasticity in adult mice. Eur $\mathrm{J}$ Neurosci 47: 1375-1384.

Teichert M, Isstas M, Liebmann L, Hubner CA, Wieske F, Winter C, Lehmann K, Bolz J (2019) Visual deprivation independent shift of ocular dominance induced by cross-modal plasticity. PLoS One 14:e0213616.

Ulanovsky N, Las L, Nelken I (2003) Processing of low-probability sounds by cortical neurons. Nat Neurosci 6:391-398.

Voss P, Lassonde M, Gougoux F, Fortin M, Guillemot JP, Lepore F (2004) Early- and late-onset blind individuals show supra-normal auditory abilities in far-space. Curr Biol 14:1734-1738.

Wehr M, Zador AM (2003) Balanced inhibition underlies tuning and sharpens spike timing in auditory cortex. Nature 426:442-446.

Wiesel TN, Hubel DH (1963) Single-cell responses in striate cortex of kittens deprived of vision in one eye. J Neurophysiol 26:10031017.

Winkowski DE, Kanold PO (2013) Laminar transformation of frequency organization in auditory cortex. J Neurosci 33:1498-1508.

Winkowski DE, Bandyopadhyay S, Shamma SA, Kanold PO (2013) Frontal cortex activation causes rapid plasticity of auditory cortical processing. J Neurosci 33:18134-18148.

Wu GK, Arbuckle R, Liu BH, Tao HW, Zhang LI (2008) Lateral sharpening of cortical frequency tuning by approximately balanced inhibition. Neuron 58:132-143.

Zhang LI, Bao S, Merzenich MM (2001) Persistent and specific influences of early acoustic environments on primary auditory cortex. Nat Neurosci 4:1123-1130.

Zhang LI, Bao S, Merzenich MM (2002) Disruption of primary auditory cortex by synchronous auditory inputs during a critical period. Proc Natl Acad Sci USA 99:2309-2314.

Zhao C, Kao JP, Kanold PO (2009) Functional excitatory microcircuits in neonatal cortex connect thalamus and layer 4. J Neurosci 29:15479-15488.

Zheng QY, Johnson KR, Erway LC (1999) Assessment of hearing in 80 inbred strains of mice by ABR threshold analyses. Hear Res 130:94-107.

Zhou X, Merzenich MM (2012) Environmental noise exposure degrades normal listening processes. Nat Commun 3:843. 